\title{
Peripheral facial palsy and mimicry after rehabilitation
}

\begin{abstract}
Introduction: Peripheral facial palsy is relatively frequent in Department of Physical Medicine and Rehabilitation. Many studies show a benefice of rehabilitation in patients with Peripheral facial palsy. In Senegal, which a developing country with little materials and human means, our aim of study was to determine in those conditions, the contribution of the rehabilitation in the management of peripheral facial palsy.
\end{abstract}

Methodology: A through a retrospective study on 1 year, 5 months, all patients followed for classical rehabilitation of peripheral facial paralysis in the Department of Physical Medicine, Fann National Teaching Hospital in Dakar, Senegal have been listed and the socio-demographic characteristics, the severity of the deficit according to the classification of Brack man and House, headquarters of the deficit and the etiology was noted. Patients, whose records have been enlisted, were summoned in February 2017 for an appreciation of the evolution of the facial paralysis and the felt functional gene.

Results: Fifty-four(54) records of patients were enrolled. The sex ratio $(\mathrm{H} / \mathrm{F})$ was 1.25 and the average age of 40,8 . Bell's palsy $(68,51 . \%)$, otitis( $16,66 \%)$ was the most frequent etiologia. The motor deficit was grade II in $18.51 \%$, III(37.2\%), IV(23.25\%), $\mathrm{V}(11.62 \%)$, VI $(9.3 \%)$. After rehabilitation, facial paralysis was grade I in $6 \%$ of cases, II(63.6\%), III(15\%), IV(9\%), V(6\%). The most expressed functional gene was about food. The leak of the drinks and the food bowl out of the mouth has been reported in $37.20 \%$ of cases.

Discussion and conclusion: The Classical Rehabilitation of Peripheral Facial Palsy in developing country, improve the functional prognosis of mimicry. According to Brack man and House Classification, mimicry of those patients, at the end of rehabilitation, corresponded largely grade I and II. Functional disability is noted in patients with peripheral facial palsy at the end of rehabilitation and interested difficult at food.

Keywords: peripheral, facial paralysis, rehabilitatio, senegal
Volume 2 Issue 2 - 2017

\author{
Diagne NS,' Maha $M,{ }^{2}$ Diop MS, ${ }^{2}$ Boubacar \\ $\mathrm{S},{ }^{2}$ Sy Abou, ${ }^{3}$ Fall M, ${ }^{4}$ Mourabit $S,{ }^{2}$ Gaye NM, ${ }^{2}$ \\ Basse $A,{ }^{2}$ Sow $A,{ }^{2}$ Ndiaye $M,{ }^{2}$ Diop $A G,{ }^{2}$ \\ Ndiaye $M^{2}$ \\ 'Department of Physical Medicine, Fann National Teaching \\ Hospital, Senegal \\ ${ }^{2}$ Department of Neurology, Fann National Teaching Hospital, \\ Senegal \\ ${ }^{3}$ Department of Psychiatry, Fann National Teaching Hospital, \\ Senegal \\ ${ }^{4}$ Department of Neurology, Pikine Hospital, Senegal
}

Correspondence: Ngor Side Diagne, Department of Physical Medicine, Fann National Teaching Hospital, Senegal, Email ngorsidediagne@gmai.com

Received: July 22, 2017 | Published: November 17, 2017

\section{Introduction}

The facial nerve is frequent. The lesions may be nuclear (Pontic) or sit on everything along its path. It is agonizing to etiological diagnosis often difficult unlike the positive diagnosis. While the contribution of the rehabilitation is more to show in peripheral facial paralysis but in a country of developing with little present rehabilitation structures and financial means allowing a sustainable rehabilitation often absent, we wanted to determine functional status, and the satisfaction of patients with peripheral facial paralysis in rehabilitation.

\section{Objective}

The main objective of our study was to determine the clinical status of facial mimicry and the existence of a potential problem in patients followed for rehabilitation of peripheral facial paralysis at Fann national teaching hospital in Dakar, Senegal (West Africa).

\section{Methodology}

We conducted a retrospective study from February $15^{\text {th }} 2017$ to March $15^{\text {th }} 2017$ at the Department of Physical Medicine and Rehabilitation, teaching Hospital, Fann, Dakar. All patients consulted in the Department of Physical Medicine and Rehabilitation, Fann National Teaching Hospital, Dakar, Senegal from July 2015 to January 2017 are registered in digital database by the only Doctor of this department.

\section{Inclusion criteria}

From this digital database, patients with Peripheral Facial palsy who beneficed to rehabilitation were included and studied parameters noted. The diagnosis of Peripheral Facial Palsy was clinical. Protocol was established by a therapist and included a relaxant massage and muscle strain of the face, strengthening the constrictor muscles especially the orbicular of the mouth and eyes and finally a work of mimicry in front of a mirror. The initial session number was ten, renewable after evaluation at the end of the first round by the same therapist. Sessions were conducted by a trained physiotherapist only help for the management of peripheral facial paralysis. The electromyostimulation was reserved to complete forms. The chungum chewing was outlawed. In Finish, Selected patients were called to a brief telephone interview conducted enjoying the satisfaction on the current facial mimicry after rehabilitation and to clarify a possible residual functional gene. Then an appointment is set with the therapist for a new assessment of the severity of the deficit.

\section{Non-inclusion criteria}

Patients with an antecedent of Peripheral Facial palsy or others neurological signs were excluded.

\section{Studied parameters}

Demographics, severity, and the seat of the motor deficit, the 
installation of the signs and symptoms, etiologies associated signs time have been noted. The associated General signs (fever, skin task, Lymphadenopathy, vesicular eruptions of the language or ear), and Otolaryngological (otorragie, otorrhoea, earache, the pressure of the external ear canal pain) have been identified.

\section{Assessment}

The severity of the motor deficit assessment was assessed by the classification of Brack man and House that has grade VI. ${ }^{1}$ The diagnosis of peripheral facial paralysis with Bell's palsy was established on an installation of disorders in 24-48 hours without other associated other signs (General, neurological and otolaryngological), outside of any pathological land known. The otolaryngology examination was carried out by a specialist in all patients with otolaryngological signs. Any peripheral facial paralysis occurred on unbalanced without other associated causes diabetic ground was attached to diabetes. A biological assessment of Free view was done systematically. It included a blood count, a speed of sedimentation, a C Reactive protein, a fasting blood sugar and retroviral to HIV serology.

\section{Results}

Fifty-four dossiers of 1283 patients $(4,2 \%)$ were enrolled. Sex $(\mathrm{M} / \mathrm{F})$ ratio was 1.25 and the average age of 40.8 years with extremes of 10 years and 88 years... Age groups [21-30 years] [31-40 years] are the most represented with respective percentages of 27,77 and 24, 07 (Figure 1). All patients were consulted before the end of the first month following the ictus. The deficit was left in $38.88 \%$, right $59.25 \%$, bilateral in 1 case. Peripheral facial paralysis was grade IIin $18.51 \%$, III(37.03\%), IV(24.07\%), V(11.11\%), VI(9.25\%). Bell's palsy at $(68.51 \%)$, otitis $(16.66 \%)$, the paratidectomia $(7.40 \%)$, traumatic fracture of $\operatorname{rock}(3.7 \%)$ were the main causes. Otitis is complicated of cholesteatoma in 2 cases. In both cases, the peripheral facial paralysis was due to diabetes. A corticosteroid therapy was initiated 15 days in $60.46 \%$ of cases, a mastoidectomia in 2 cases. After rehabilitation, $62 \%$ of patients were satisfied with the results and expressed no disability (Figure 2). The most expressed functional gene was about food. The leak of the drinks and the food bowl out of the mouth was reported in $37.20 \%$ of cases.

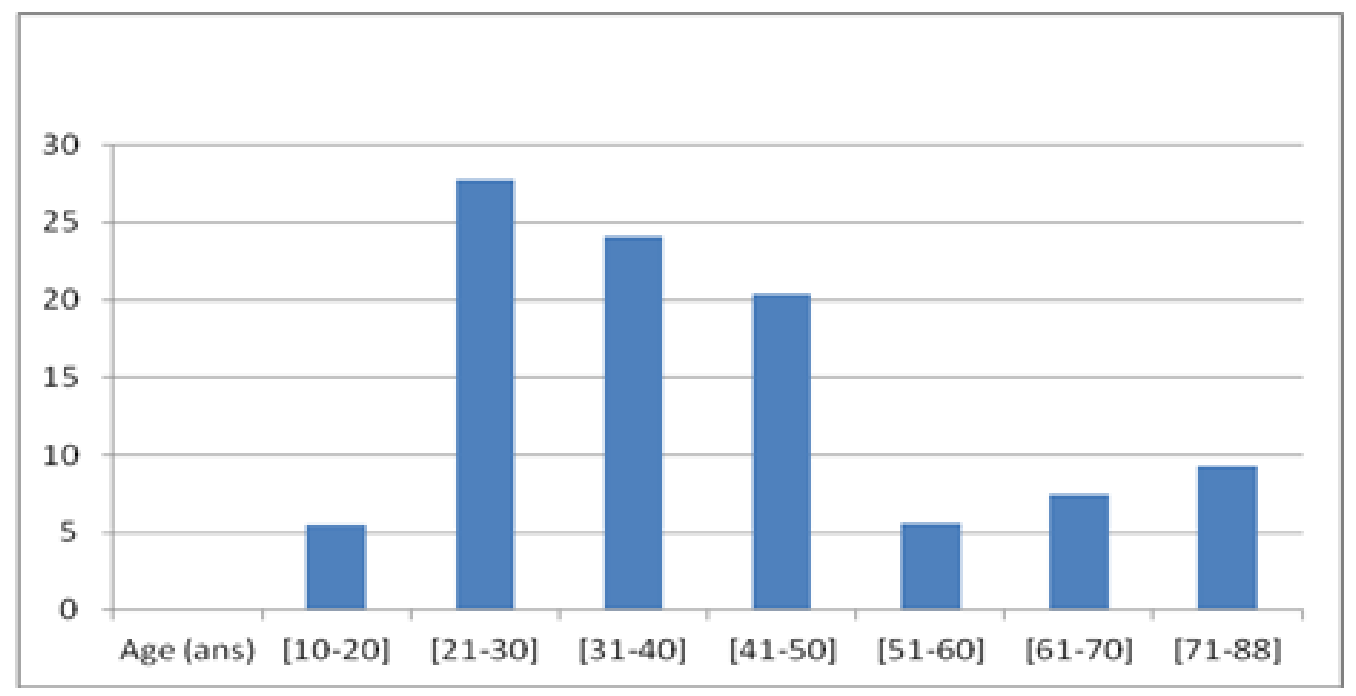

Figure I Frequency by age.

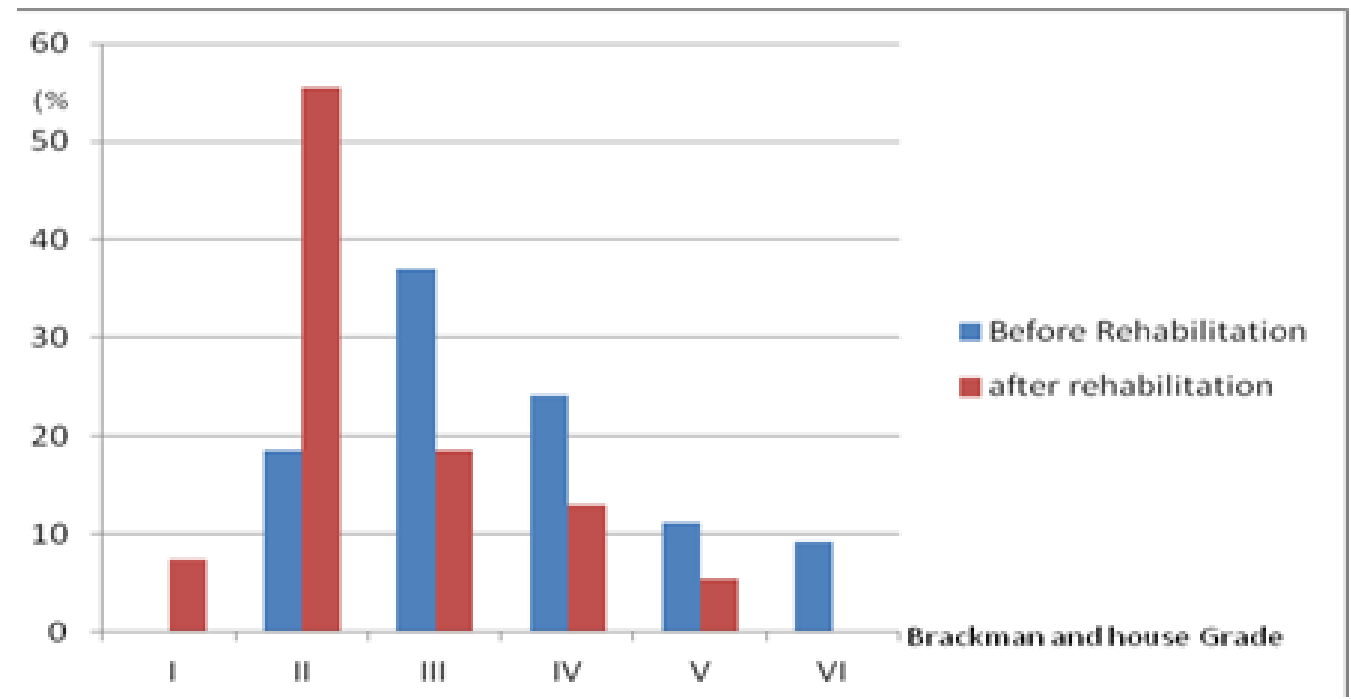

Figure 2 Mimicry of patients before and after rehabilitation. 


\section{Discussion}

The peripheral facial paralysis is a relatively common condition. In the United States, specifically in Rochester, the incidence of idiopathic peripheral facial paralysis is of $20-30$ cases by 100.000 habitants ${ }^{2}$ and $60-70 \%$ of peripheral facial paralysis. ${ }^{3}$ The frequency of peripheral facial paralysis is little determined in Africa. In the Physical Medicine Department of Youpougon University Hospital, it's $3.90 \%{ }^{4}$ against $4.2 \%$ in our study. Peripheral facial paralysis more frequently affects adults in their thirties. ${ }^{3,4,7-9}$ The etiological diagnosis of facial paralysis peripheral is not easy and requires a rigorous and methodical approach, which consists in finding clinical signs (General, neurological and otolaryngological) in disfavor of the Bell's palsy that remains of far the commonest. ${ }^{4,10,11}$ Thus, peripheral Bell's palsy is far the most frequent., ${ }^{4,9,12}$ In Africa, ear infections are the second cause of peripheral facial paralysis., ${ }^{4,12}$ This is one effect from our data. It is mentioned that HIV infection is often revealed by a peripheral facial paralysis. ${ }^{5-7}$ Therefore, a retroviral serology must be requested before any peripheral facial paralysis in sub-Saharan Africa. We has no HIV infection in our study.

Taking account of the quality of the studies in rehabilitation management Bell's palsy, the benefit remains mixed. There is evidence of low quality on the improvement of the facial function with targeted exercises muscles of the face. This benefit is particularly described in people with moderate and chronic paralysis. Rehabilitation can also reduce the consequences in cases acute. ${ }^{13}$ In Our study $81,55 \%$ of patients have a grade of less than or equal III after rehabilitation against $55,54 \%$ before rehabilitation for the same grade. This means that, consequences of peripheral facial palsy can be reduced in high grade of Brachman and House classification (IV, V, VI) with classical rehabilitation. In Senegal, it's uncommon to got full recovery after peripheral facial palsy but more than $50 \%$ of patients can obtain grade II. Bombo and $\mathrm{al}^{4}$ in Abidjan, noted that the rehabilitation of peripheral facial paralysis, allowed a total recovery in $42,42 \%$ of the cases, partial but satisfactory in $34,85 \%$, partial type 2 in $22,73 \%$ of cases. ${ }^{4}$ Their results are better than ours. Whatever the type of facial rehabilitation established (classic or mirror), only the age and the free range, ${ }^{14,9}$ have been identified as factors that may influence the recovery after peripheral facial paralysis. A free range is defined by the time between the installation of peripheral facial paralysis at the consultation in a service of physical medicine and rehabilitation. ${ }^{9}$ According to those data, for explain the differences we noted that, the population was younger in Abidjan study than ours, their free range, unknown, and their evaluation at the end of the rehabilitation less accurate. Knowing the role of facial muscles in the diet, and the speech, our study tried to highlight the existence of disruption on these functions. Our results confirm a satisfactory facial function in patients in rehabilitation.

\section{Conclusion}

Peripheral Facial palsy is relatively common in the department of Physical Medicine, in sub-Saharan Africa and affected young people. Etiologic are largely dominated by Bell Palsy. Despite of a limited equipment and humans' resources in developing country, Classical Rehabilitation, introduced in the first month, improve functional prognosis of mimicry. Full recovery is noted in few patients. The most frequent grade presented after rehabilitation is II according to Brack man and House Classification. The only functional disorder noted is the leak of the drinks and the food bowl out of the mouth

\section{Acknowledgements}

None.

\section{Conflict of interest}

The authors declared no conflicts of interest.

\section{References}

1. François M. Traitement de la paralysie faciale périphérique chez l'enfant. Med Enfance. 2004;487-489.

2. Hauser WA, Karnes WE, Annis J, et al. Incidence and prognosis of bell's palsy in the population of rochester, Minnesota. Mayo Clin Proc. 1971;46(4):258-264.

3. Adour KK, Byl FM, Hilsinger RL, et al. The true nature of Bell's palsy: Analysis of 1,000 consecutive patients. Laryngoscope. 1978 ;88(5):787801.

4. J Bombo, B Manou, AD Alloh, et al. Place de la rééducation dans le traitement des paralysies faciales périphériques : Expérience du Service de Médecine Physique et de Réadaptation du CHU Youpougon, Abidjan. JRM. 2008;28(1):3-6.

5. DG Avode, A Bigot, N Kodjoh. Paralysie faciale périphérique isolée et sérologie rétrovirale positive du VIH. Une étude de 6 cas au CHNU de Cotonou, Benin. Medecine d'Afrique Noire. 1996;43:490-493.

6. Diallo, D Kanikomo, CO Guindo, Touré M, et al. La paralysie faciale périphérique peut elle être une manifestation neurologique révélatrice de l'infection à VIH. Revue Malienne d'Infectiologie et de Microbiologie. 2014;(2):54-61.

7. Millogo A, Ki Zerbo GA, Sawadogo AB, et al, Paralysie faciale périphérique étude prospective et relation avec l'infection à VIH au CHNSS de Bobbo Dioulasso. Med Afr Noire. 1997;44:8-9.

8. Millogo A, Ki Zerbo GA, Sawadogo AB, et al. Caractéristiques compares des paralysies facials peripheriques selon le statut VIH a Bobbo Dioulasso. Bull Pathol Exot. 2000;3:104-107.

9. Rakotorisoa AHN, Ratovao RFE, Razafindrakoto RMJ. Résultats de la rééducation de la paralysie faciale à Frigore au CHU d'Antananarivo. Revue d'Odontostomatologie Malgache. 2012;(4):29-36.

10. Lamas G, Barbut J, Mamelle E, et al. Rééducation de la face paralyse. Bilan pré-thérapeutique du patient: Ann Chir Esthet; 2015.

11. Peitersen I. Natural history of Bell's Pulsy. Acta otolaryngol 1992;492:122-124.

12. Boudjenah F, Dehl H, Ouazar B, et al. La paralysie faciale périphérique: Expérience du service. 2012;129(4).

13. Teixeral J, Valbuza JS, Prado GF. Physical therapy for Bell's Pulsy. Cochrane Data Base of Systematic Reviews. 2011;7(12).

14. Danielidis V, Skevas A, Cauwenberge P, et al. A Comparative Study of age and degree of facial nerve recovery in patients with Bell's Pulsy. Eur Arch Oto rhino laryngol. 1999;256(10):520-522. 